\title{
INSIDER VS OUTSIDER IN THE CULTURE OF THE SOLIDARY COMMUNITY: MEANINGS AND VALUES
}

\author{
Olga N. Astafyeva ${ }^{1}$, Natalia E. Sudakova ${ }^{2^{*}}$, Irina G. Belyakova ${ }^{3}$ \\ ${ }^{1}$ Dr. Prof., The Russian Presidential Academy of National Economy and Public Administration, \\ Russia, on.astafyeva@migsu.ru \\ ${ }^{2}$ Assist. Prof. Dr., The Russian Presidential Academy of National Economy and Public \\ Administration, Russia, sovetnik.imtp@mail.ru \\ ${ }^{*}$ Corresponding author \\ ${ }^{3}$ Assist.Prof. Dr., The Russian Presidential Academy of National Economy and Public \\ Administration, Russia, ig.belyakova@migsu.ru \\ ${ }^{*}$ Corresponding author
}

\begin{abstract}
The relevance of the presented research is conditioned by the need to comprehend the semantic and value bases of the coexistence of human civilization in the vector of a solidary community, striving to accept each other in all its singularity and uniqueness of the sociocultural life in the context of aggravation of social problems caused by various aspects of social inequality strengthening. The comprehension of this issue is very urgent today, since it allows us to build a system of counterbalances to the rapidly growing social antagonisms allowing not only to overcome many of them, but also to anticipate them. At the forefront in this context comes the reflection of the Insider vs Outsider opposition in the situation of increasing need for a solidarity community.

The purpose of the research is to understand the mechanisms of overcoming the alienation of the opposition Insider vs Outsider in the face of growing need, on the one hand, in solidarity, tolerant being, and on the other hand, in preserving the unique traditional cultural patterns of everyone, in which in the foreground is the search for a balance allowing not only to find the common strengthening cohesion, but also to manifest a difference without exacerbating tension in the relationship. These orientations are vital in the current situation, due to the increased intensity of social interaction in all its manifestations, both local and civilizational, exacerbating conflicts at all levels.

The basic method of research for determining all aspects of this problem is the socio-cultural analysis expanded by the possibilities of philosophical reflection.

The presented concept allows us to focus attention on the sociocultural aspects of the diversity of unique cultural patterns as the basis of social cohesion in the conditions of increasing multiculturalism both in Russia and in the whole world. Increasing mobility is the basic characteristic of our time, further exacerbating the manifestation of multiculturalism on a personal and social levels, thus showing that it increases the need for comprehension of the mechanisms for maintaining a balance between personal and social, general and unique, in that it allows not only to distinguish and compare Insider vs Outsider, but to extinguish the tension within this opposition.
\end{abstract}


Comprehension of this problem is of great importance, both on personal and social levels, since each person has a need for social incarnation, where the individual's possibility for not only feeling himself as a part of the whole but also for showing his unique nature to the world becomes paramount. Thus, the findings and conclusions of the study indicate that the manifestation of the common and unique is the essence of human nature, and maintaining a balance in preserving the common and unique is the basis for preserving the human species, in which Insider vs Outsider opposition is the basic model of human civilization identifying the truly human nature.

Keywords: Insider, Outsider, solidary community, multiculturalism, tension, diversity, tolerance.

\section{INTRODUCTION}

The universality of the opposition Insider vs Outsider has appeared on the agenda for many centuries of the human civilization existence. Demonstrated in our time, taking into account the updated reality, it, however, does not lose its relevance. Some new forms of interpersonal interaction emerging today contribute to this fact.

Manifesting themselves in all the areas of human life, new forms of interpersonal communication, which are one way or another directly related to the act of co-creation and communication with representatives of another culture, give rise to the need to create a new space of social solidarity of nowadays, taking into account the opposition of Insider vs Outsider. Co-creation, which manifests itself on a very different scale: from individuals' interaction to different kinds of communities, is not only the basic principle of the existence of a person in particular and society as a whole, but also a tool for creating your one's culture that defines a person as a person, a nation as an ethnic group, and humanity as a civilization.

The tendencies to global inter-penetration, often formulated by the scientific community as the decline of ethnic and cultural identity, are in many ways expected, and already quite noticeable: they are changing the vector of their development towards the preservation of the national cultures' uniqueness, provoking many related problems.

Of course, the modern world is replete with evidence of cultural trends' inter-penetration that erode the value foundations of traditional culture. We are witnessing the emergence of various global practices of cultural coexistence, but we are also witnessing attempts to preserve cultural identity as opposed to global unification at all the levels of human civilization. Many modern thinkers convince us that the global project of globalization as of universal unification is gradually completing its development. Turning to the views of Ivan Krastev (2013), of a macro-sociologist Zygmunt Bauman (2004, 2005, 2006), political scientists Peter Dutkevich (University of Carlton, Canada), D. Kazarinova, state the widespread loss of trust in the two institutions of the world order - "in the state (Keynesianism) and in the market (neo-liberalism)" (Dutkevich, Kazarinova, 2017). In this concept two philosophical categories are put out of brackets: uncertainty and fluidity, which aggravate the disintegrating processes of the established model of individuals coexistence in the global reality. Generating fear of the unknown, they force the individual and the community to look for ways of self-organization, giving at least some confidence in the future. In search of stability, a person rushes to similar ones, so-called His Native, Insiders, and even more moves away from everything Alien

These trends significantly expand the themes of solidarity, with the idea that "in the context of global transit, the question of alignment and solidarity of interests, values and potentials of all public relations participants comes to the forefront, so the social theory of solidarism, which for this question is the key one, acquires a new meaning and very real prospects of demand" (Okara, 2010, P.8.).

Solidarity, conditioned by the individuals' growing need for joint creativity that meets the interests of both themselves and Others, is a key factor in the modern communications harmonization, in the center of which there is the recognition of equal importance of each of its members for the society, while for the global context - of all existing cultures equivalence. A necessary condition for this interaction is trust towards each other, where the need for both tolerant existence and the preservation of unique traditional cultural patterns of a man and of whole ethnic groups is rapidly increasing. In this context, the understanding is actualized that the designated categories, having the appearance of opposition, are inseparable parts of the whole only by accepting their personal, including cultural characteristics, comprehending their importance for themselves and for the society, it is possible to truly accept and understand the value world of another person. It is also obvious that the lack of satisfaction from the formation and development of one's system of 
value coordinates, the lack of understanding of their deep essential importance for every single personality, for the society around you, generates no understanding of the needs and values of Another's, Outsider's world.

Thus, the theory of solidarism acquires new meanings today by understanding the mechanisms of overcoming the alienation of the Insider vs Outsider opposition where the tradition of domination is gradually replaced by the trend of co-existence in the context of solidarity, which is quite significant, both at the micro level - the level of small communities, such as families, and at the macro-level, in the process of creating civilizational unions. These trends are being seriously discussed by the global community. This theme is actively discussed and studied by many authors, including E.I. Balakina (2011), E.E. Surova (1998), B. Waldenfels (1994, 1998), I. Wallerstein (2004), D. Rodrik (2011), M. Bennet, L. Castiglioni (2004).

Turning to the problems of de-globalization, Vasil Prodanov (2017), emphasizes the fact that monopolarity as a trend which is actively gaining its positions from the beginning of the seventies of the XX century up to the present day, is gradually giving way to the multipolar paradigm, where the processes of the world order hierarchy disintegration come to their inevitable outcome. We are witnessing many symptoms of cultural deglobalization, where national interests, patriotic sentiments and cultural identity are actively gaining ground, including through growing ethnic and religious conflicts.

The destruction of the value foundation based on a strict hierarchy (we are talking about the socio - cultural organization of society as a whole), the human civilization's entering the so-called "orbit of individual strategies", where systemic social institutions are gradually losing their influence on the individual, the emergence of new information branches of interpersonal interaction actualize the global search for tools of coexistence in the vector of non-violence. In this context, many pressing problems are exposed, including the lack of trust or the tools to nurture it in the modern world.

One of the urgent effects of this trend was the growing need for self-organization and reflection in various communities and, as a result, the active imposition of this model on all management systems. On the agenda, there are various issues of identity related to the awareness of the person's belonging to a particular culture, with the ability and need to transfer this cultural experience to future generations. And here, various aspects of the national idea are even more pronounced - they rediscover that very Pandora's box from which nationalism in its most vulgar forms descends upon us. How can we maintain a much-needed balance between the national and the global idea, between native and frightening foreign culture today? How can we avoid falling into the newly placed traps, luring us to the sweet heart of national and cultural superiority idea, but not lose our unique face in the depths of globalization? Are there any tools of identification and solidarity that can optimize this process and direct it along the vector of nonviolence?

It is obvious that the problem of Insider vs Outsider opposition which sounds in a new way and especially actively shows itself in search of tools of the arising tension release along the vector of a solidary community creation, demands the active, also philosophical discourse.

\section{WORLD SEARCHING FOR BALANCE: LITERATURE REVIEW AND METHODOLOGY}

Updating the semantic content of this problem determines the vectors of its development. In the age of informatization and rapidly increasing mobility, a person conceptualizes his/her true purpose and place in the human community in a new way, forms a new vision of his own identity. A wisdom expressed in the proverb: "where one was born there one was useful - grows where you are planted" is no longer the only possible model of existence.

Today, many communities, most often not even thinking about the consequences, actively promote the "man of the world's" lifestyle. Many opportunities opened up by the new technologies development allow us to meet countless new and emerging needs. Money becomes a tool that expands this circle to infinity. And here we see a situation where social status, high level of education and other intangible values, previously demanded by the society, lose their value, giving way to a model of existence, striving to achieve maximum opportunities to meet a wide range of needs.

A serious change in the previously existing stereotypes is confirmed by the situation when several worldfamous companies, including such giants as Google, Ernst \& Young (EY), Penguin Random House, Hilton, Publix, Apple, Starbucks, IBM, Bank of America, announced that the lack of a higher education diploma is no longer an obstacle in hiring for a number of high-paying positions: "'Academic qualifications will still be taken into account and indeed remain an important consideration when assessing candidates as a whole, but will no longer act as a barrier to getting a foot in the door," added Maggie Stilwell, Ernst and Young's managing partner for talent» (Glassdoor Team. August 14, 2018). The stunning nature of this statement is confirmed by 
the fact that this was written in many major publications in the world. And this is understandable, because getting a systematic education has been the main value of human civilization for the last few centuries, and a huge number of people around the world have worked and are still working on its development. Yet here, of course, the main thing is not the denial of education as such, but the recognition of the possibility of obtaining it outside the traditional system of higher education. It is assumed that modern technologies give a person the opportunity to get the necessary education outside any educational systems.

Changes in value orientations are also demonstrated by other phenomena, including the need for constant mobility, which has replaced the tradition of settlement, contributing to the emergence of a sufficiently large number of people who do not want to profess traditional cultural values: "to build a house, plant trees and raise children." Thus, the values of permanent work and a full-fledged family are actively reset. The society of needs satisfaction dictates new markers of success for individuals, but many of them are not aimed at understanding the other, his/her values, but rather make us people who are completely indifferent to each other. As a result, anyone whom a person interacts with becomes a Stranger, because everyone is some threat for the individual, for the satisfaction of his/her needs. How close is the dead end here?

In our opinion, the situation becomes critical, when the emergence of new opportunities for communication, allows a person not to participate in personal interaction at all, because it can be replaced by all sorts of surrogates. This thesis actively manifests itself in the world of the victorious virtual communicative culture, where even the most ordinary human needs are met with the help of virtual interaction tools. The real format of communication literally recedes into the background, because it requires some, primarily emotional, efforts, which becomes unacceptable in the era of the informational world.

This problem requires the human community to use the methods of deep socio-cultural analysis, because otherwise we can really lose the human face, being created for thousands of years by sustainable personal interaction with other people.

\section{TOOLS OF SOCIAL AND CULTURAL SOLIDARITY: RESULTS AND DISCUSSION}

A personal meeting with an Outsider scares the person so much that it becomes obvious - all means of modern interaction are aimed at avoiding its consequences, disturbing the emotional world of man in all possible ways. Moreover, an axiom - whether a personality really needs anybody Else for his/ her selfidentity - is actively questioned? We're observing the time when the "child-free" culture walks the planet. People cease to marry or postpone this time, because it requires long-term interaction with another person (different from you in all respects), and responsibility for him/her and the society. The era of "self-sufficiency of the individual" gave rise to the phenomenon of Strangers in the format of one family: vacation separately from each other, a separate economy, as well as living in different apartments, houses, cities, and even continents. The need to care for another person, including one's own child, is replaced by an increasing need to satisfy only one's own desires. The problem of Insider vs Outsider opposition else's acquires more and more new meanings, condemning the traditional values that have allowed humanity to survive for thousands of years - to death.

As a result, a new model of personal identification is formed, focused on success in its modern understanding, where the cultural traditions of the residence region lose their value. But this model, which, of course, is still subject to wide discussion, hardly has everything necessary to become the basis for the harmonious existence of the individual in the future. It is obvious that a person as a social being feels satisfaction from belonging to some community, from the presence of ancestral culture in his life, from the recognition of his own importance for the life of a social group. The loss of this orientation leads to deep social deformities. The need for social significance is one of the main markers of human life, where traditions and values have been important for thousands of years. By identifying oneself and people who profess values close to yours via Insider vs Outsider opposition, the person gets the opportunity to feel oneself being a part of the whole, to feel the stability of his/her own life connected with this fact.

According to L. N. Vinogradova, Insider vs Outsider antithesis "is conceptualized in the categories of multilevel human relations: blood-related (one's own - another clan, family), ethnic (my - another tribe, nationality, nation), language (native-foreign language, dialect) confessional (own - foreign religion), social (own-foreign community, class, collective), etc. Treating "strangers" as hostile and dangerous to human beings goes back to the archaic beliefs that all people who came from afar and do not belong to the nearest community are representatives of the "alien" world and are endowed with supernatural properties", where something "alien" was literally assigned demonic characteristics, even at the level of the name, identifying it as "inhuman" in many languages. (Vinogradova L. N., 1995, P. 17).

Such ideas about the person from the opposition point of view, have their active manifestation in Slavic mythology, yet their traces can be seen today as well. Insider vs Outsider opposition, being an essential 
need and a characteristic of the human species, not varying at its base, nevertheless seriously actualizes and shows us its new form. The principle of opposition, having deep roots in the tradition of human coexistence, significantly affects social cohesion, the formation of which is very important for modern society, including in the search for tools of socio-cultural solidarity, which is of particular value in the context of the formation of national identity.

Speaking about identity, G. Shpet emphasized that the involuntary nature of national identification is relative, since it is determined by the specific cultural environment in which the person was brought up, the native language and traditions close in perception (Sokolovskaya, 2012). They form the basis for the conscious and voluntary adoption of norms, values, behavioral rules. Accordingly, a special angle of view is built on the socio-cultural reality and the system of communication in it, on the worldview.

"Culture in the modern world is becoming a common synonym of identity," S. Benhabib says (Mokin, Baryshnaya, 2009). But if we are talking about intercultural communication, then cultural identity acts as a classifier on the Insider vs Outsider principle. This process is complex and internally contradictory. On the one hand, social groups build strong ties between people with similar values: "we" and "our" become markers of collective identity. On the other hand, it is this process of cohesion that causes tension in relation to the "foreign" culture representatives.

Thus, cultural identity divides the participants of the communication process into "friends" and "foes", and such a division leads to the need to include the strengthening of collective identity into the strategic objectives of the state cultural policy. The fact is that in the case of excessive disunity and increased attention to cultural differences, the process of self-identification can take a conflict character. It is well known that "to identify themselves, people need others. But above all, they need enemies." (Civilizational identity in the transitional era: cultural, sociological and art criticism, 2011). So others become Strangers and predetermine the increase of conflict with a foreign environment.

From what it follows that it is the opposition on the Insider vs Outsider principle, as a starting point for the growth of tension, on the other hand, is actively exploited in the modern world as a tool for stabilization within communities, because in the conditions of the endless fluidity of modern reality, it carries a significant potential to overcome the growing fears of the unknown future in society today. Identifying his / her sociocultural experience with a Stranger, a person tends to turn a blind eye to many internal problems, both personal and within his / her community, which, of course, contributes to the stabilization and solidarity of social communities.

The problem of the Stranger is not limited to other people's experience, it carries a negative character. Unlike another, a Stranger is always a danger. The protection of one's own cultural values is a necessary condition for human existence, but the danger of one's superiority over Another is determined by a derogatory attitude to one's culture and needs, and therefore, one way or another, has a serious conflict provoking potential. This approach leads not only to an underestimation of the Stranger's culture, but also to its denial, and therefore contributes to its rejection and isolation. Quite often there is a situation where mobility in the modern culture, due to the ability to live, learn and work anywhere in the world, begins to be perceived with hostility. This is facilitated by the rejection of Another's special culture, unusual for the region, which becomes Alien to the host culture and its carriers. An example of this is the flow of migrants from different continents, which has caused a serious surge of negativity in different countries of the European Union. And this situation is rapidly getting worse. Strangers are more and more growing in number; they are so many that almost all around become alien Strangers, Outsiders. How can we survive in this situation? This issue is actively discussed at many sites around the world.

In the process this phenomenon spread, the positions of tolerant attitude to Another, as a carrier of another culture, but not a danger to the individual, are strengthened. Recognition of the unconditional value of the other becomes a necessary condition for harmonious co-existence. For countries previously dominated by mono-cultural perceptions, recognition of this approach viability is difficult. But respect for the cultural characteristics of others, helps the society to redirect the excess of negative feelings into a positive direction, contributing to the emergence of sustainable empathy for Another.

In this context, an American cultural anthropologist M. Bennett's views on the Insider vs Outsider problems are of interest (Bennet M., 2004. P.249). He claimed that interaction in the context of Insider vs Outsider opposition includes two stages: ethnocentric and ethno-relative. These phases are a natural process of evolution of one's own attitude to the differences and peculiarities of Another's personality. The first phase concentrates the person on himself, and therefore, all the features of another culture are perceived by him through rejection. Denying the foreign culture, brimming with superiority, he protects what is precious and dear to him. The second phase is characterized by the development of understanding and acceptance of the 
Other's personality, the recognition of the value of his culture, which not only forms empathy towards another culture, but also contributes to its integration into the host community.

Recognition of the foreign culture's importance is not possible without acquaintance with it. Even on the territory of the Russian Federation, in which more than 190 Nations have lived together for a long time, we can observe situations when representatives of different nationalities are not sufficiently familiar with the culture of other people's living nearby. If we talk about other countries, the biggest problem is, in our opinion, that the people living nearby speak different languages and do not have the tools for deep acquaintance with each other's culture. It is quite common that only the inhabitants of the border areas are familiar with both the culture and the language of their neighbors.

Today, the range of opportunities for cultural exchange is expanding significantly. The European Union is an example of the peaceful coexistence of multilingual peoples in a single space where many people need to learn about the culture of the peoples living in the neighborhood. The EU experience is of interest, due to the established practice to actively study a Foreign culture (neighbors' culture) during the "weekend" trips. The size of the Russian Federation territory, its climatic features and the instability of the economic situation seriously hampered the development of intercultural cooperation within the country for the last quarter of the previous century, but today the situation is changing and domestic tourism is developing again. This is facilitated by information technology, which has become widespread in recent years, the absence of language barriers, the improvement of the economic situation in the country. Actively developing domestic tourism allows peoples who have been living in Russia for many centuries to interact with each other. Having their own language and unique national culture, knowing Russian, but due to heavy transport accessibility, not having the opportunity before - they now can actively study the culture of their neighbors by direct immersion.

This experience allows us to conclude today that the recognition of the value significance of cultural differences, as well as the recognition of the distinctive features of each person, not only determine the value bases of our time, but are also an inevitable consequence of the evolutionary development of human civilization. The transition from the previous demonization of the Alien to the acceptance of him as the owner of other, but no less important, and therefore equivalent for the society cultural imperatives, there is a transition to a multicultural civilization, where the bicultural and multicultural practices of coexistence are being actively developed. The ability to "discover the Other" without perceiving him/her as a Stranger is one of the most important abilities of human survival in modern reality.

Summarizing the above, we can conclude that the understanding of Familiar vs Alien culture place in the life of man and society is a very important task of modern science, which is particularly relevant to the possibility of the individual to be a part of the whole, to feel one's social significance, showing the world its own unique Self. Achieving balance with the world and oneself in the process of communication, allowing a person to feel his/her importance is impossible without Insider vs Outsider opposition, without a person's meeting with culture different from their own.

Modern science has yet to seriously comprehend this phenomenon and develop mechanisms for decreasing the "alien" to the level of "otherness", in order to harmonize the process of co-existence, to form a stable Foundation for productive co-creation for the benefit of the whole human civilization.

\section{CONCLUSIONS}

Thus, the Insider vs Outsider opposition is the basic principle of human coexistence, where the dialog between the two cultures leads both to unity and to the assertion of one's own uniqueness, where one cannot exist without the other, and the balance in the preservation of the common and unique is the basis for the preservation of the human species. This principle makes the base for the mechanism of stabilization in the conditions of endless fluidity of modern reality, which is able to overcome the growing boom of fears of the future in society today. This principle allows both individuals and communities, acting as full participants in the co-creation act, to build interaction in the context of solidary coexistence.

Understanding this problem is essential, both in personal and social terms, because every born person has a need for social embodiment, where the ability of the individual not only to feel a part of the whole, but also to show the world its unique essence is of paramount importance.

Today, when the intensity of social tension is high enough, which is associated with the ever-increasing pace of interpersonal interaction, which appeared as a result of technologization and informatization of the society, the question of conflict resolution methods is very significant. The methods of overcoming the emerging tension associated with the Insider vs Outsider opposition carry a serious potential for resolving many social issues, being one of the significant factors influencing various aspects of the strategic partnership of the 
entire world community. Thus, there is no doubt about the importance of this issue for the modern scientific and political community, where one of the strategic objectives of the state policy is the task of strengthening collective identity.

\section{REFERENCE LIST}

Astafyeva, O.N. (2015). Cultural Policy and National Culture: Prospects of the Strategic Vector of Modern Russia / O.N. Astafyeva, G.A. Avanesova // Yaroslavl Pedagogical Bulletin, No. 5, pp. 193-201. (In Russ.)

Astafyeva, O.N. (2014). Theoretical Foundations of Cultural Policy and Integration of the Idea of Culture into the Public Discourse // Librarianship, № 6, pp.13 - 18. (In Russ.)

Astafyeva, O.N. (2018). Overcoming risks of "dialogue gaps" in non-linear cultural environment.

Astafyeva, O. N., Belyakova, I. G., Sudakova, N. E. (2017). Theoretical Studies of Mass Culture as a SelfDeveloping System in the Context of the Tasks of Russia's Cultural Policy. Eurasian Journal of Analytical Chemistry; 12 (Interdisciplinary Perspective on Sciences 7b): pp. 1475-1481.

Balakina, E.I. (2011). Dialog as a way of transforming "another's" into "one's own". Barnaul; Rubtsovsk: Publishing house Alt. University, 2011. pp. 73-82. (In Russ)

Bauman, Z. (2004). Globalization. Consequences for man and society / Z. Bauman. Moscow, All the World, 188p. (In Russ)

Bauman, Z. (2005). 44 Letters from the Liquid Modern World. Cambridge: Polity.

Bauman, Z.(2006). Liquid Fear. Cambridge: Polity.

Bauman, Z. (2006). Liquid Times: Living in an Age of Uncertainty. Cambridge: Polity.

Bauman, Z. (2004), Wasted Lives: Modernity and its Outcasts, Polity Press,Cambridge, U.K.

Belyakova I.G.(2016). New Models of Intercultural Communication: Strategic Coherence of the Language, Social, and Cultural Policies of Singapore. Observatory of Culture; 13(3):280-286. (In Russ.)

Belyakova, I.G. (2018). Specifics of Models of Modern Professional and Business Communication through the Prism of Intercultural Competency Formation. Publications of SGEM 2018. Albena, Bulgaria: SGEM. pp. 4-10.

Belyakova, I.G. ( 2017). Language variety in modern global socity: language of intercultural communication as a factor of sociocultural integration. 4th International Multidisciplinary Scientific Conference on Social Sciences and Arts SGEM 2017, Book 2, Vol 2, pp. 33-39.

Bennet, M., Castiglioni, L. (2004). Embodied Ethnocentrism and the Feeling of Culture. Landis ,D., Bennet, J.M., Bennet, M. Handbook of Intercultural Training, 3 rd Ed. Sage Publ. 528p.

Dutkevich, P, Kazarinova, D. (1017). The end of globalization: reasons and consequences. Bulletin of the Peoples' Friendship University of Russia. Series: Political Science (RUDN Journal of Political Science). Vol. 19, No. 1. Pp.7-14. (In Russ)

Glassdoor Team. August, 14, 2018. 15 More Companies That No Longer Require a Degree-Apply Now.

Globalization and interdependence: culture and development. (2013). Report of the Second United Nations Committee (A / 68/440 and Add.1-4 of 13 December 2013) at the UN General Assembly. Access mode: http://www.un.org/en/ga/second/72/documentslist.shtml (reference date: 14.08.2018)

Humanistic turn: imperative of human civilization: monograph. (2018). By N.N. Zarubina, G.N. Ilyina, D.N. Karpova, etc. Under the general editorship of S. A. Kravchenko. Moscow: MGIMO-University, 209 p.

Insider/Outsider: American Jews and Multiculturalism Paperback . (1998). by David Biale (Editor), Michael Galchinsky (Editor), Susannah Heschel (Editor), 288 p. Publisher: University of California Press.

Insiders and Outsiders: Citizenship and Xenophobia in Contemporary Southern Africa (Africa in the New Millennium) (2006). by Francis B. Nyamnjoh . Series: Africa in the New Millennium, 288p. Publisher: Zed Books. 
Insiders and Outsiders: Dilemmas of East European Jewry (Littman Library of Jewish Civilization). (2010). 1st Edition by Richard I. Cohen (Editor), Jonathan Frankel (Editor), Stefani Hoffman (Editor); Series: Littman Library of Jewish Civilization, 262p. Publisher: Littman Library Of Jewish Civilization.

Krastev, I. (2013). In Mistrust We Trust: Can Democracy Survive When We Don't Trust Our Leaders? TED books, 3 January 2013.

Mokin, K.S., Baryshnaya, N.A. (2009). Ethnopolitical research: concepts, methodology, practice. Saratov: Science. (In Russ)

Okara, A. N. (2010). Social solidarity as a basis for a new "peace-building" project. P.8. Synergy, № 9. (In Russ.

Prodanov, V. (2017). From globalization to de-globalization. International Likhachev Readings. Plenary session "The Global World: Systemic Shifts, Challenges and Contours of the Future". pp.173-175. (In Russ)

Rodrik, D. (2011). The Globalization Paradox. Norton \& Company, Inc.

Sokolovskaya, I.E. (2012). Psychological phenomenon of identity of religious youth. Vestnik MGOU. Psychological sciences, №3. (In Russ)

Sudakova, N. E. (2018). Inclusion as a Value Core of the Philosophy of Humanism, Observatory of Culture, vol.15, no. 1, pp.21-31. DOI: 10.25281 / 2072-3156-2018-15-1-21-31. (In Russ.)

Sudakova, N. E. (2016). Philosophical reflection of inclusion as a phenomenon of modern culture: towards the Other. Historical, Philosophical, Political and Law Sciences, Culturology and Study of Art. Issues of Theory and Practice, vol.11, P.1, Tambov, pp.152-154. (In Russ.)

Sudakova, N.E. (2018). Philosophical reflection of inclusive education being a part of the Russian sociocultural space: on the way to inclusive culture. Proceedings of SOCIOINT 2018-5th International Conference on Education, Social Sciences and Humanities, 2-4 July 2018- Dubai, U.A.E.pp.69-76. ISBN: 978-605-82433-3-0. Access mode: http://www.ocerints.org/socioint18_epublication/abstracts/papers/159.pdf

Sudakova N.E. (2018). The phenomenon of inclusion in the perspective of philosophical reflection: Russia on the way to the accepting society. Publications of SGEM 2018. Albena, Bulgaria:SGEM. pp. 48-53.

Surova, E. E., Waldenfels, B. (1998). "Sting of the Stranger" (Fragment) Translation, Foreword and Afterword. Metaphysical Studies. Consciousness. SPb, № 5. pp. 161-184. (In Russ)

"Strategy of the state cultural policy for the period until 2030". (2016). Order of the Government of the Russian Federation of February 29, 2016 No. 326-r. Access mode: http://static.government.ru/media/files/AsA9RAyYVAJnoBuKgH0qEJA9IxP7f2xm.pdf (reference date: 14.08.2018) (In Russ)

Tsivilizatsionnaya identity in the transitional era: cultural, sociological and art criticism. (2011). Moscow: Progress-Tradition. (In Russ)

Vinogradova, L. N. (1995). Human/Unhuman in the popular perception. Monograph: Man in the context of culture. Slavic world./Chief editor I. I. Svirid. Moscow, 240p. (In Russ) http://inslav.ru/images/stories/pdf/1995_Chelovek_v_kontekste_kul\%27tury_Slav\%27anskij_mir.pdf

Waldenfels, B. (1994). Own culture and foreign culture. The paradox of science about a stranger.Translation of O.Kubanova. Logos number 6. pp.77-94. (In Russ)

Wallerstein, I. (2004). The End of the World as We Know It: Social Science in the Twenty-first Century. Moscow, Logos. (In Russ) 